\title{
Document Version Keyword Code
}

National Cancer Institute

\section{Source}

National Cancer Institute. Document Version Keyword Code. NCI Thesaurus. Code C93815.

A coded value specifying the words or phrases that best describe the document and/or its context. Keywords help users find documents of interest. 